\title{
Gestão do conhecimento: uma análise baseada em fatores contextuais da organização
}

\author{
Rodrigo Valio Dominguez Gonzalez ${ }^{\mathrm{a} *}$, Manoel Fernando Martins ${ }^{\mathrm{b}}$ \\ a*Universidade Estadual de Campinas, Campinas, SP, Brasil, rodrigo.gonzalez@fca.unicamp.br \\ bUniversidade Federal de São Carlos, São Carlos, SP, Brasil
}

\begin{abstract}
Resumo
Os modelos mais recentes sobre Gestão do Conhecimento (GC) reconhecem quatro fases para a sua prática: aquisição, armazenamento, distribuição e utilização do conhecimento. A GC se caracteriza como uma disciplina multidisciplinar, envolvendo aspectos de ordem técnica e social e devido à diversidade de assuntos que cerca esse tema, é essencial delimitar seu estudo. Nesse sentido, o recorte proposto para esta pesquisa é social e de coordenação, tendo como objetivo a identificação de fatores contextuais, desenvolvidos internamente às organizações, que sustentam o processo de GC em empresas do setor automobilístico. Para atingir esse objetivo é utilizado um método de pesquisa quantitativo, baseado em uma pesquisa survey. Os resultados obtidos apontam para a existência de oito fatores contextuais que sustentam o processo de GC. Esses fatores são relacionados essencialmente ao ser humano, responsável pela retenção e transformação do conhecimento primário, e ao desenvolvimento de um contexto organizacional que estimule o processo de aprendizagem.
\end{abstract}

Palavras-chave

Gestão do conhecimento. Aprendizagem organizacional. Fatores contextuais. Setor automobilístico. Análise multivariada de dados.

\section{Introdução}

A noção de que o conhecimento é recurso organizacional capaz de gerar vantagem competitiva (Grant, 1996) e, ainda, que sua característica intangivel e componente tácita é responsável por gerar diferencial de difícil imitação por parte dos concorrentes (Choo, 1998; Nelson \& Winter, 1982) já é consolidada no mundo acadêmico, tornando-se fundamental a gestão desse ativo, isto é, a gestão do conhecimento (GC).

Ainda que muitos de seus pontos centrais não sejam novidades para o mundo acadêmico, o estudo da Gestão do Conhecimento é um conceito recente, discutido mais intensamente na década de 1990, tratado como um processo que promove o fluxo do conhecimento entre indivíduos e grupos da organização constituído de quatro etapas essenciais: aquisição, armazenamento, distribuição e utilização do conhecimento (Alavi \& Leidner, 2001; Cormican \& O'Sullivan, 2003).

Dessa forma, a missão principal da GC é criar um contexto organizacional que estimule o desenvolvimento de novos conhecimentos, por meio da aprendizagem explorativa e explotativa (March, 1991) ou de single e double loop (Argyris \& Schön, 1978), além de criar artifícios que possibilitem a retenção do conhecimento, seja ele tácito ou explícito, a fim de que possa ser distribuído aos indivíduos da organização para sua utilização em atividades de rotina, melhoria incremental ou inovação, gerando vantagem competitiva (Carlile \& Rebentisch, 2003).

Davenport \& Prusak (1998) e Lytras \& Pouloudi (2006) enfatizam a importância do desenvolvimento de uma cultura e estrutura organizacional que fomentem o sentido de cooperação e troca de informação entre grupos e indivíduos e também do desenvolvimento da mão de obra (agente responsável pela manifestação do conhecimento) para o êxito da GC. Contudo, a literatura voltada para a GC não detalha, de forma estruturada, os fatores internos e contextuais às organizações que sustentam o processo de GC. 
As organizações desenvolvem internamente fatores, denominados, neste artigo, contextuais. Tal denominação deve-se ao fato de que eles estabelecem o comportamento organizacional, do ponto de vista cultural, dos recursos humanos e de suas formas de relacionamento, da estrutura e do modo como o conhecimento é desenvolvido e absorvido, os quais se relacionam com o processo de GC: a aquisição, o armazenamento, a distribuição e a utilização do conhecimento. Sem o empenho quanto ao desenvolvimento desses fatores, quaisquer iniciativas organizacionais voltadas para a GC acabam não resultando nos benefícios esperados (Gupta \& Govindarajan, 2000). Dessa forma, o objetivo principal deste artigo é a identificação do grupo de fatores contextuais que sustentam o processo de GC em organizações do setor automobilístico.

A escolha desse setor pode ser justificada em dois sentidos. 0 primeiro refere-se à sua importância dentro da indústria brasileira. Segundo a Associação Nacional dos Fabricantes de Veículos Automotores - ANFAVEA (2012), esse setor emprega 5,6\% dos funcionários da indústria brasileira e é responsável por 19,8\% do PIB industrial. Outra justificativa refere-se à capacidade de inovação do setor.

\section{Processo de gestão do conhecimento}

Autores como Argote et al. (2003), Lee \& Yang (2000) e Yang (2010) tratam a GC como um processo com fases específicas, as quais têm como objetivo central a disseminação do conhecimento, para sua posterior reutilização por outros indivíduos e grupos e consequente transformação de seu conteúdo, gerando novos conhecimentos.

Pelo fato de o conhecimento consistir em uma evolução de dados e informação, Alvesson \& Kärreman (2001) argumentam que o processo de GC é mais complexo que a gestão da informação. Ainda atendo-se a essa definição, vale ressaltar que conhecimento está relacionado à ação humana (Sveiby, 1997) e, dessa forma, depende de indivíduos com competências suficientes para adquiri-lo, compreendê-lo e desenvolvê-lo. E, além disso, o sucesso na implementação desse processo é condicionado ao desenvolvimento de características organizacionais adequadas que propiciem o desenvolvimento de quatro fases: aquisição, armazenamento, distribuição e utilização do conhecimento (Durst \& Edvardsson, 2012; Zheng et al., 2010; Liao et al., 2011; Zack, 1999).

A aquisição refere-se ao processo intraorganizacional que facilita a criação de conhecimento tácito e explícito, partindo dos indivíduos e integrando-se ao nível organizacional, bem como a identificação e absorção de informação e conhecimento de origem externa (Gold et al., 2001; Huber, 1991). 0 processo de aquisição ainda está relacionado com o estímulo organizacional em torno da aprendizagem dos indivíduos que torne a firma apta em integrar, construir e reconfigurar suas competências internas, a fim de responder às mudanças ambientais (Teece, 2007; Cohen \& Levinthal, 1990), promovido por meio do desenvolvimento de uma cultura voltada à aprendizagem (Skerlavaj et al., 2007; Irani et al., 2009).

0 estágio de armazenamento do conhecimento refere-se ao processo de formação de memória organizacional (Walsh \& Ungson, 1991), na qual o conhecimento é formalmente armazenado em sistemas físicos de memória relacionados a sistemas de informação (SI), informalmente retido na forma de valores, normas e crenças que se associam à cultura e estrutura organizacional (Alavi \& Leidner, 2001), e também retido nos processos, ferramentas e rotinas organizacionais (Kane \& Alavi, 2007). A firma, nesse contexto, passa a ter conotação de repositório de conhecimento (Grant, 1996), caracterizando-se como um local físico que sustenta a criação e desenvolvimento, provendo um contexto social.

A distribuição do conhecimento diz respeito ao processo pelo qual novas informações de diferentes origens são compartilhadas e, eventualmente, podem dirigir a criação de novo conhecimento, entendimento e informação (Lee \& Yang, 2000). Os trabalhos mais antigos acerca do processo de transferência de conhecimento tinham como ênfase fatores cognitivos e sociais. Atualmente, o foco está sobre os fatores organizacionais que facilitam ou inibem o processo de transferência, incluindo capacidade absortiva da organização (Cohen \& Levinthal, 1990), o desenvolvimento de uma cultura de compartilhamento (Skerlavaj et al., 2007), expertise desenvolvida pelos indivíduos (Cross \& Sproull, 2004), aspectos motivacionais (Quigley et al., 2007) e tecnologia que facilita o processo de transferência (Figueiredo, 2005; Kane \& Alavi, 2007).

Em relação à fase de utilização do conhecimento, Zack (1999) a define como a habilidade dos indivíduos de uma organização de localizarem, acessarem e utilizarem informação e conhecimento armazenados nos sistemas de memória formal e informal da organização.

\section{Constructos associados ao contexto organizacional que promovem a GC}

Esta pesquisa parte da premissa que a GC é um fenômeno técnico-social (Lytras \& Pouloudi, 2006; Lin, 2007) e, dessa forma, as etapas do processo 
de GC estão condicionadas ao desenvolvimento organizacional. Esta seção tem por objetivo determinar os constructos organizacionais que promovem cada fase do processo de GC.

\subsection{Desenvolvimento de recursos humanos}

Muitas organizações enfrentam o obstáculo decorrente da "herança" do modelo taylorista de produção em relação ao desenvolvimento de novos conhecimentos, bem como a sua posterior distribuição e utilização por parte de seus integrantes. Tal modelo, baseado na separação dos planejadores do processo (pensadores) e operadores (executantes), defronta-se com as propostas mais modernas de gerenciamento e organização do sistema produtivo, as quais fincam seus valores em trabalho e resolução de problemas em grupo, amplo envolvimento por parte dos trabalhadores, além de identidade e objetivos compartilhados.

As abordagens mais modernas relacionadas ao tratamento dos recursos humanos partem de premissas voltadas ao desenvolvimento da mão de obra, visando o aprimoramento constante das competências (Zangiski et al., 2013; Zarifian, 2001; Leonard-Barton, 1992).

As iniciativas de GC dependem da disposição de as pessoas compartilharem seus conhecimentos e expertise (Quigley et al., 2007; Amayah, 2013). Nenhuma organização pode gerar conhecimento sem pessoas habilitadas (Cross \& Sproull, 2004; Zarifian, 2001). E ainda, por meio das práticas de desenvolvimento de recursos humanos, as organizações podem desenvolver uma cultura organizacional que encoraje a aquisição e o compartilhamento do conhecimento (Zangiski et al., 2013).
A Tabela 1 levanta as principais variáveis e respectivos autores do constructo Desenvolvimento de Recursos Humanos relevantes para a GC.

\subsection{Trabalho em equipe}

A visão da organização como máquina (Morgan, 1996) torna-se cada vez mais ultrapassada quando se visa estudar uma forma de gestão que propicie a constante aquisição e distribuição do conhecimento, ou seja, um fluxo intenso de conhecimento (Rowley, 2001). Por conta dessa prerrogativa, a GC depende de um contexto social alicerçado por trabalho em equipe - grupos que compartilham ideias e competências profissionais (Brown \& Duguid, 2001; Orlikowski, 2002) -, que promova a aprendizagem contínua dos indivíduos.

0 trabalho em equipe é uma das principais características das formas mais modernas de organização do trabalho, como a manufatura enxuta e grupos semiautônomos (Tanskanen et al., 1998). Existem diferentes projetos de trabalho em grupo, por exemplo, enquanto na manufatura enxuta o conceito de grupo é focado na utilização de procedimentos operacionais e hierarquia bem definida, com supervisão rígida, nos grupos, baseado num modelo sociotécnico, existe certo grau de autonomia quanto à escolha do melhor método de trabalho, além de uma hierarquia mais enxuta (Schuring, 1996).

Um aspecto central para a efetividade do trabalho em grupo é o processo de integração do conhecimento (Okhuysen \& Eisenhardt, 2002; Turner et al., 2012). Para que se torne útil, o conhecimento individual, que é propriedade dos indivíduos, deve ser integrado ao grupo por meio de um processo de assimilação e interpretação (Crossan et al., 1999) e institucionalizado

Tabela 1. Variáveis e principais autores do constructo Desenvolvimento de Recursos Humanos.

\begin{tabular}{|c|c|c|}
\hline Aspectos relevantes & Autores & Variáveis \\
\hline \multirow{2}{*}{$\begin{array}{l}\text { Utilização de método } \\
\text { estruturado de mapeamento } \\
\text { e avaliação de competências }\end{array}$} & \multirow{2}{*}{$\begin{array}{l}\text { Zarifian (2001); Fleury \& Fleury } \\
\text { (2000) }\end{array}$} & $\begin{array}{l}\text { RH1: A empresa possui um método estruturado para a avaliação das } \\
\text { competências exigidas dos funcionários }\end{array}$ \\
\hline & & $\begin{array}{l}\text { RH2: Os gestores acompanham e avaliam constantemente o } \\
\text { desenvolvimento de seus subordinados }\end{array}$ \\
\hline Recrutamento e seleção & Dibella et al. (1996) & $\begin{array}{l}\text { RH8: } 0 \text { processo de recrutamento valoriza a postura criativa e o espírito } \\
\text { empreendedor }\end{array}$ \\
\hline $\begin{array}{l}\text { Programas de treinamento e } \\
\text { qualificação }\end{array}$ & Cross \& Sproull, 2004 & $\begin{array}{l}\text { RH3: A empresa oferece cursos/palestras aos funcionários para o } \\
\text { aprimoramento das competências }\end{array}$ \\
\hline $\begin{array}{l}\text { Sistema de incentivo e } \\
\text { recompensa }\end{array}$ & $\begin{array}{l}\text { Leonard-Barton (1992); Amayah } \\
\text { (2013); Quigley et al., } 2007\end{array}$ & $\begin{array}{l}\text { RH6: A empresa apresenta mecanismos de premiação e recompensas por } \\
\text { resultados atingidos }\end{array}$ \\
\hline \multirow[b]{2}{*}{ Postura proativa } & \multirow{2}{*}{$\begin{array}{l}\text { Fleury \& Fleury (2000); Zarifian } \\
\text { (2001) }\end{array}$} & RH4: Os profissionais da empresa buscam o autodesenvolvimento \\
\hline & & $\begin{array}{l}\text { RH5: Os profissionais da empresa estão capacitados a tomarem decisões } \\
\text { e gerenciarem riscos }\end{array}$ \\
\hline $\begin{array}{l}\text { Entendimento dos objetivos } \\
\text { organizacionais }\end{array}$ & Zarifian (2001) & $\begin{array}{l}\text { RH7: Os funcionários reconhecem a importância de seu trabalho em } \\
\text { relação à estratégia da empresa }\end{array}$ \\
\hline Polivalência & $\begin{array}{l}\text { Leonard-Barton (1992); Nonaka \& } \\
\text { Takeuchi (1995) }\end{array}$ & $\begin{array}{l}\text { RH9: Os funcionários são altamente polivalentes, isto é, exercem } \\
\text { diversas funções relativas ao seu processo de trabalho }\end{array}$ \\
\hline
\end{tabular}


na organização (Grant, 1996), para que possa ser explotado, a fim de gerar vantagem competitiva para a organização.

A Tabela 2 levanta as principais variáveis e respectivos autores do constructo Trabalho em Equipe.

\subsection{Cultura organizacional}

A literatura existente em GC constantemente salienta a inseparável relação existente entre cultura organizacional e GC (Davenport \& Prusak, 1998; Skerlavaj et al., 2007). A pesquisa realizada por Davenport \& Prusak (1998) aponta que quando uma organização adota um sistema de gerenciamento do conhecimento sem se preocupar com o desenvolvimento cultural que o propicie, a eficiência da GC é limitada.

0 survey realizado por Alavi \& Leidner (2001) demonstra que grande parte do sucesso das iniciativas de GC é advinda de uma adequação cultural que estimula os funcionários a compartilharem o conhecimento tácito adquirido por meio da experiência nas atividades de rotina e no processo de resolução de problemas denominada cultura do conhecimento.

Huber (1991) define a cultura do conhecimento como os pressupostos estabelecidos pela organização que valorizam o compartilhamento e a integração do conhecimento entre indivíduos e grupos. Em relação à questão do compartilhamento do conhecimento, Gold et al. (2001) concluem que as organizações com valores mais abertos e voltados para o apoio recíproco entre os indivíduos são predispostas a construirem uma cultura do conhecimento.

A Tabela 3 levanta as principais variáveis e respectivos autores do constructo Cultura Organizacional relevantes à GC.

\subsection{Estrutura organizacional}

Chen \& Huang (2007) definem estrutura organizacional a partir de três elementos: a formalização, a centralização e a integração.

A formalização refere-se ao nível de codificação de regras e procedimentos que guiam o comportamento dos trabalhadores. Em organizações altamente formalizadas, a existência de documentos formais inibe a geração de ideias e impede o comportamento espontâneo necessário ao estímulo às inovações (Gilson \& Shalley, 2004).

A centralização está relacionada à concentração do poder decisório nos altos níveis hierárquicos (Andrews \& Kacmar, 2001). A centralização cria um ambiente não participativo, reduzindo a comunicação, o comprometimento e o envolvimento entre os funcionários e ainda impede que os funcionários tomem decisões acerca de seu trabalho, causando ineficiência na criação e compartilhamento do conhecimento (Janz \& Prasarnphnich, 2003).

A integração refere-se ao grau de interrelacionamento entre indivíduos e setores da organização. A GC requer um fluxo intenso de comunicação entre membros de diferentes setores da organização e as estruturas em rede estimulam o compartilhamento de informação e conhecimento por parte dos indivíduos (Wilkinson \& Young, 2006; Liao et al., 2011). As estruturas em rede oferecem oportunidades para os trabalhadores aprenderem conjuntamente, pois elas facilitam a construção de canais de comunicação para o compartilhamento de conhecimento (Chen et al., 2010).

A Tabela 4 levanta as principais variáveis e respectivos autores do constructo Estrutura Organizacional.

Tabela 2. Variáveis e principais autores do constructo Trabalho em Equipe.

\begin{tabular}{|c|c|c|}
\hline Aspectos relevantes & Autores & Variáveis \\
\hline $\begin{array}{l}\text { Atividades de rotina e } \\
\text { melhorias executadas em } \\
\text { grupo }\end{array}$ & $\begin{array}{l}\text { Schuring (1996); London \& Sessa } \\
\text { (2007) }\end{array}$ & $\begin{array}{l}\text { TE1: Os projetos de trabalho são realizados, em sua maioria, em grupos } \\
\text { que executam e analisam conjuntamente os resultados }\end{array}$ \\
\hline linguagem comum & $\begin{array}{l}\text { Orlikowski (2002); Brown \& } \\
\text { Duguid (2001) }\end{array}$ & $\begin{array}{l}\text { TE5: Os funcionários de um determinado setor ou grupo criam uma } \\
\text { linguagem comum entre eles, relativa ao processo de trabalho }\end{array}$ \\
\hline \multirow{2}{*}{$\begin{array}{l}\text { Autonomia para a tomada de } \\
\text { decisão operacional }\end{array}$} & \multirow{2}{*}{$\begin{array}{l}\text { Schuring (1996); London \& Sessa } \\
\text { (2007) }\end{array}$} & $\begin{array}{l}\text { TE3: A empresa oferece aos funcionários autonomia para resolverem } \\
\text { problemas operacionais }\end{array}$ \\
\hline & & $\begin{array}{l}\text { TE6: Os funcionários dos grupos de trabalho têm a capacidade de se } \\
\text { autogerenciarem, isto é, capacidade de auto-organização }\end{array}$ \\
\hline \multirow{3}{*}{$\begin{array}{l}\text { Interação entre os } \\
\text { funcionários do grupo }\end{array}$} & \multirow{3}{*}{$\begin{array}{l}\text { Turner et al. (2012); Brown \& } \\
\text { Duguid (1991) ; Lee et al. (2013) }\end{array}$} & $\begin{array}{l}\text { TE2: A empresa incentiva o aprendizado e a troca de informações entre } \\
\text { os funcionários }\end{array}$ \\
\hline & & $\begin{array}{l}\text { TE4: A organização estimula a interação entre funcionários de } \\
\text { diferentes especialidades }\end{array}$ \\
\hline & & $\begin{array}{l}\text { TE8: Os funcionários de um grupo têm ciência dos conhecimentos e } \\
\text { habilidades dominados por seus colegas de trabalho }\end{array}$ \\
\hline $\begin{array}{l}\text { ldentidade do funcionário } \\
\text { frente ao grupo }\end{array}$ & $\begin{array}{l}\text { Schuring (1996); Eisenhardt } \\
\text { (1989); Lee et al. (2013) }\end{array}$ & $\begin{array}{l}\text { TE7: É perceptível que os funcionários de um determinado setor ou } \\
\text { grupo de trabalho sentem-se "donos" daquela área }\end{array}$ \\
\hline
\end{tabular}


Tabela 3. Variáveis e principais autores do constructo Cultura Organizacional.

\begin{tabular}{|c|c|c|}
\hline Aspectos relevantes & Autores & Variáveis \\
\hline \multirow{3}{*}{$\begin{array}{l}\text { Estímulo ao compartilhamento } \\
\text { do conhecimento }\end{array}$} & \multirow{3}{*}{$\begin{array}{l}\text { Alavi \& Leidner (2001); } \\
\text { Gold et al. (2001); } \\
\text { Skerlavaj et al. (2007); } \\
\text { Zheng et al., (2010) }\end{array}$} & $\begin{array}{l}\text { C01: Os funcionários costumam trocar informações e experiências } \\
\text { quando se deparam com um problema }\end{array}$ \\
\hline & & $\begin{array}{l}\text { C02: Após seções de treinamento, os funcionários interagem sobre os } \\
\text { conhecimentos adquiridos }\end{array}$ \\
\hline & & $\begin{array}{l}\text { C04: Quando um funcionário apresenta uma ideia ou projeto de } \\
\text { melhoria existe a cooperação dos demais colegas }\end{array}$ \\
\hline $\begin{array}{l}\text { ldentificação e interesse do } \\
\text { funcionário em relação à } \\
\text { empresa }\end{array}$ & De Long \& Fahey (2000) & $\begin{array}{l}\text { C03: Os funcionários estão cientes quanto à evolução da empresa e de } \\
\text { suas necessidades individuais de qualificação }\end{array}$ \\
\hline \multirow{3}{*}{$\begin{array}{l}\text { Atuação participativa dos } \\
\text { superiores }\end{array}$} & \multirow{3}{*}{$\begin{array}{l}\text { lrani et al. (2009); Prajogo \& } \\
\text { McDermott (2011) }\end{array}$} & $\begin{array}{l}\text { C05: Quando um funcionário apresenta uma ideia ou projeto de } \\
\text { melhoria existe o reconhecimento de seu superior }\end{array}$ \\
\hline & & $\begin{array}{l}\text { C06: Existe uma comunicação constante entre funcionários e gerência } \\
\text { sobre a situação da empresa }\end{array}$ \\
\hline & & $\begin{array}{l}\text { C09: Os gestores da empresa conseguem identificar as melhores práticas } \\
\text { nos processos pelos quais são responsáveis }\end{array}$ \\
\hline \multirow{2}{*}{ Postura de assumir riscos } & \multirow{2}{*}{$\begin{array}{l}\text { lrani et al. (2009); De Long \& } \\
\text { Fahey (2000) }\end{array}$} & $\begin{array}{l}\text { C07: A empresa apresenta uma cultura que estimula seus funcionários a } \\
\text { tomarem decisões e assumirem riscos inerentes a seus processos }\end{array}$ \\
\hline & & $\begin{array}{l}\text { C08: A empresa interpreta eventuais erros cometidos pelos funcionários } \\
\text { como parte do processo de aprendizagem }\end{array}$ \\
\hline
\end{tabular}

Tabela 4. Variáveis e principais autores do constructo Estrutura Organizacional.

\begin{tabular}{|l|l|l|}
\hline \multicolumn{1}{|c|}{ Aspectos relevantes } & \multicolumn{1}{|c|}{ Autores } & \multicolumn{1}{c|}{ Variáveis } \\
\hline $\begin{array}{l}\text { Fluxo de informação e } \\
\text { conhecimento horizontal }\end{array}$ & $\begin{array}{l}\text { Wilkinson \& Young (2006); Garicano } \\
\text { \& Wu (2012) }\end{array}$ & $\begin{array}{l}\text { EO2: Existe facilidade de comunicação entre os setores ou } \\
\text { departamentos da empresa }\end{array}$ \\
\hline Estrutura vertical enxuta & $\begin{array}{l}\text { Stewart (1998); Andrews \& Kacmar } \\
\text { (2001) }\end{array}$ & $\begin{array}{l}\text { EO1: A empresa possui poucos níveis hierárquicos, isto é, verticalmente, } \\
\text { ela apresenta uma estrutura enxuta }\end{array}$ \\
\hline Mudanças internas & Ostroff (1999) & $\begin{array}{l}\text { E04: A empresa consegue mudar quando necessário a estrutura de } \\
\text { departamentos, cargos e atribuições }\end{array}$ \\
\hline Integração funcional & $\begin{array}{l}\text { Nonaka \& Takeuchi (1995); Ostroff } \\
\text { (1999); Chen \& Huang (2007); } \\
\text { Wilkinson \& Young (2006) }\end{array}$ & $\begin{array}{l}\text { E05: É comum diversos projetos ou atividades envolverem } \\
\text { simultaneamente dois ou mais setores da empresa }\end{array}$ \\
\hline Armazenamento do \\
$\begin{array}{l}\text { conhecimento em bancos } \\
\text { de dados integrados }\end{array}$ & $\begin{array}{l}\text { Figueiredo (2005); Leonard-Barton } \\
\text { (1992) }\end{array}$ & $\begin{array}{l}\text { E03: Existe grande interesse da organização em estabelecer } \\
\text { procedimentos, métodos ou instruções para as atividades }\end{array}$ \\
\cline { 2 - 3 } & $\begin{array}{l}\text { E06: Os sistemas de informação da empresa estão integrados, sendo } \\
\text { possivel que qualquer área da empresa tenha acesso ao conteúdo das } \\
\text { demais áreas }\end{array}$ \\
\cline { 2 - 3 } & $\begin{array}{l}\text { E07: As melhores práticas de cada departamento são registradas em um } \\
\text { banco de dados }\end{array}$ \\
\hline $\begin{array}{l}\text { Utilização de ferramentas } \\
\text { de socialização do } \\
\text { conhecimento }\end{array}$ & $\begin{array}{l}\text { Faraj et al. (2011); Leidner \& Elam } \\
\text { (1995) }\end{array}$ & $\begin{array}{l}\text { E09: A empresa apresenta ambientes virtuais para discussão entre os } \\
\text { funcionários (fóruns virtuais, grupos de e-mails, MSN, entre outros) }\end{array}$ \\
\hline $\begin{array}{l}\text { Acesso à base de } \\
\text { conhecimento }\end{array}$ & Figueiredo (2005); Faraj et al. (2011) & $\begin{array}{l}\text { E08: Existe amplo acesso ao banco de dados da empresa, } \\
\text { independentemente do nivel hierárquico do funcionário }\end{array}$ \\
\hline
\end{tabular}

\subsection{Desenvolvimento e absorção de conhecimento}

A capacidade de absorção refere-se à habilidade de uma organização em reconhecer o valor de determinado conhecimento, assimilá-lo e aplicá-lo, visando obter vantagem competitiva (Cohen \& Levinthal, 1990). Segundo os autores, a noção fundamental desse conceito concentra-se no fato de que as organizações precisam acessar seu conhecimento primário para assimilar e utilizar novos conhecimentos, isto é, o acúmulo de conhecimento primário aumenta o potencial de aprendizagem futura.

Enquanto organizações com maior nível de capacidade de absorção tendem a ser mais dinâmicas
(Teece et al., 1997; Volberda et al., 2010), isto é, aptas a explorarem oportunidades no ambiente, independentemente da performance atual; as organizações com menor nível de capacidade de absorção tendem a ser mais reativas, pois procuram formas para a correção de suas falhas, baseando-se em padrões de desempenho que não significam avanço tecnológico. Os conceitos de reatividade e proatividade organizacional são de longo prazo, isto é, as firmas que atingem um nível proativo, por exemplo, permanecem dessa forma pela sua própria aspiração de pesquisar novas oportunidades (Cohen \& Levinthal, 1990).

Exploração e explotação representam dois modelos fundamentalmente diferentes de 
aprendizagem organizacional. 0 primeiro implica em um comportamento da firma voltado à pesquisa, descoberta e experimentação; enquanto o segundo caracteriza-se pelo refinamento, implementação, eficiência, produção e seleção (March, 1991). 0 autor ainda enfatiza que os retornos associados à exploração são mais variáveis e de longo prazo, enquanto os retornos relacionados à explotação são mais precisos e de curto prazo.

A Tabela 5 levanta as principais variáveis e respectivos autores do constructo Desenvolvimento e Absorção de Conhecimento.

\section{Método de pesquisa}

Durante o levantamento dos objetivos da pesquisa e do referencial teórico pode-se concluir que esta pesquisa possui um caráter exploratório em função de existirem lacunas de compreensão entre a GC e os fatores contextuais que a delineiam. Como o interesse deste trabalho é identificar fatores organizacionais que sustentam a GC dentro de um setor, uma pesquisa de natureza quantitativa apresenta maior robustez por abranger uma amostra maior de organizações (Bryman, 1989).

Os dados coletados nesta pesquisa são do tipo primário, utilizando-se, para tanto, o método survey. A escolha do survey para esta tese deve-se essencialmente à possibilidade de obtenção de uma maior abrangência em relação à população estudada (empresas do setor automobilístico), a qual permita o tratamento multivariado dos dados. Além disso, a abordagem quantitativa possibilita a generalização dos resultados, pois a amostra coletada apresenta representatividade dentro do setor automobilístico. Forza (2002) propõe o procedimento para desenvolvimento desse tipo de pesquisa, conforme Tabela 6 .

Em relação à análise dos dados foi adotado o método de análise fatorial, que constitui uma técnica estatística exploratória, destinada a resumir um conjunto de variáveis em um conjunto de fatores não observáveis, denominado análise fatorial tipo R (Hair Junior et al., 2005). Na presente pesquisa, a análise fatorial permite condensar um conjunto grande de variáveis, composto originalmente por 46 variáveis, em conjunto reduzido de fatores, o que permite a identificação e melhor caracterização dos fatores que sustentam o processo de GC. Vale ressaltar ainda que 0 procedimento de análise fatorial permite ao pesquisador identificar, dentre o conjunto de variáveis, aquelas que melhor se relacionam com os fatores retidos e também eliminar as variáveis que eventualmente não são representativas para a definição dos fatores que sustentam a GC. A Figura 1 ilustra os passos do método de análise fatorial seguidos nesta pesquisa.

\section{Resultados}

\subsection{Caracterização das empresas e entrevistados pesquisados}

A primeira análise realizada visa compreender o porte das empresas pesquisadas. Todas as empresas consideradas pela pesquisa são de médio ou grande

Tabela 5. Variáveis e principais autores do constructo Desenvolvimento e Absorção de Conhecimento.

\begin{tabular}{|c|c|c|}
\hline Aspectos relevantes & Autores & Variáveis \\
\hline \multirow{2}{*}{$\begin{array}{l}\text { Capacidade de absorver novos } \\
\text { conhecimentos }\end{array}$} & \multirow{2}{*}{$\begin{array}{l}\text { Cohen \& Levinthal (1990); } \\
\text { Grant (1996) }\end{array}$} & $\begin{array}{l}\text { CAbs5: A empresa tem facilidade na aplicação de novas tecnologias e } \\
\text { conhecimentos }\end{array}$ \\
\hline & & CAbs8: A empresa antecipa inovações no mercado em que concorre \\
\hline \multirow[b]{2}{*}{ Explorar novos conhecimentos } & \multirow{2}{*}{$\begin{array}{l}\text { March (1991); Levinthal \& } \\
\text { March (1993); Crossan et al. } \\
\text { (1999) }\end{array}$} & CAbs1: A empresa desenvolve novas tecnologias internamente \\
\hline & & $\begin{array}{l}\text { CAbs7: A empresa domina a tecnologia envolvida em sua área de } \\
\text { atuação }\end{array}$ \\
\hline \multirow{3}{*}{$\begin{array}{l}\text { Utilização do conhecimento } \\
\text { existente, a fim de aumentar a } \\
\text { competitividade }\end{array}$} & \multirow{3}{*}{$\begin{array}{l}\text { March (1991); Levinthal \& } \\
\text { March (1993); Crossan et al. } \\
\text { (1999) }\end{array}$} & $\begin{array}{l}\text { CAbs2: } 0 \text { conhecimento desenvolvido pelos funcionários é utilizado em } \\
\text { atividades de melhoria }\end{array}$ \\
\hline & & $\begin{array}{l}\text { CAbs9: As competências desenvolvidas internamente facilitam à } \\
\text { empresa explorar novas oportunidades no mercado }\end{array}$ \\
\hline & & $\begin{array}{l}\text { CAbs10: A empresa possui um método estruturado para solução de } \\
\text { problemas (procedimento, utilização de ferramentas, formação de } \\
\text { equipes etc.) }\end{array}$ \\
\hline \multirow[t]{2}{*}{ Acesso a novas tecnologias } & \multirow[t]{2}{*}{ Eisenhardt \& Martin (2000) } & $\begin{array}{l}\text { CAbs4: A empresa tem fácil acesso a novas tecnologias (originadas de } \\
\text { especialistas externos, de universidades, parceria com outras empresas } \\
\text { etc.) }\end{array}$ \\
\hline & & $\begin{array}{l}\text { CAbs11: A empresa adquire novos conhecimentos por meio de aquisição } \\
\text { de patentes ou em parceria com outras organizações.) }\end{array}$ \\
\hline \multirow{2}{*}{$\begin{array}{l}\text { Capacidade de reconstruir suas } \\
\text { competências internas }\end{array}$} & \multirow{2}{*}{ Teece et al. (1997) } & $\begin{array}{l}\text { CAbs3: A utilização do conhecimento e das competências adquiridos ao } \\
\text { longo do tempo mantém a empresa competitiva frente aos concorrentes }\end{array}$ \\
\hline & & $\begin{array}{l}\text { CAbs6: Os processos e atividades praticados rotineiramente evoluem } \\
\text { com o tempo }\end{array}$ \\
\hline
\end{tabular}


Tabela 6. Procedimento de pesquisa.

\begin{tabular}{|c|c|}
\hline Passos & Ações tomadas \\
\hline $\begin{array}{l}\text { 1. Elaborar a questão de } \\
\text { pesquisa }\end{array}$ & $\begin{array}{l}\text { A questão que orienta esta pesquisa é: Quais são os fatores contextuais da organização que relacionam-se } \\
\text { com o processo de GC dentro do setor produtivo empresas automobilísticas? }\end{array}$ \\
\hline $\begin{array}{l}\text { 2. Definir amostra de } \\
\text { empresas e funcionários a ser } \\
\text { pesquisada }\end{array}$ & $\begin{array}{l}\text { Empresas amostradas aleatoriamente a partir do banco de dados do SINDIPEÇAS (Sindicato Nacional da } \\
\text { Indústria de Componentes para Veículos Automotores brasileiro). A pesquisa considera apenas as empresas } \\
\text { instaladas no estado de São Paulo devido à sua alta representatividade dentro da indústria automobilística } \\
\text { brasileira. Das } 544 \text { empresas identificadas no catálogo do SINDIPEÇAS, foram filtradas } 455 \text { empresas do } \\
\text { estado de São Paulo, ou 83,6\%. Em relação aos funcionários pesquisados, foram considerados os cargos de } \\
\text { direção, gerência e supervisão dos departamentos voltados a produção, engenharia, qualidade e recursos } \\
\text { humanos. }\end{array}$ \\
\hline $\begin{array}{l}\text { 3. Desenvolver um } \\
\text { questionário de pesquisa }\end{array}$ & $\begin{array}{l}0 \text { questionário desta pesquisa é constituído de duas partes. A primeira abrange informações que caracterizam } \\
\text { a empresa e o entrevistado. A segunda parte foi desenvolvida a partir dos cinco constructos e grupos de } \\
\text { variáveis (tabelas de } 1 \text { a 5), sendo as variáveis avaliadas por meio de questões fechadas numa escala Likert de } \\
\text { seis pontos, variando entre } 1 \text { (Nunca praticada ou observada) e } 6 \text { (Faz parte da rotina da empresa). }\end{array}$ \\
\hline 4. Promover teste piloto & $\begin{array}{l}0 \text { teste piloto foi conduzido por meio de duas etapas. A primeira consistiu na aplicação do questionário a um } \\
\text { conjunto de } 12 \text { profissionais de empresas do setor metal-mecânico brasileiro e sete acadêmicos da área de } \\
\text { engenharia de produção, com a finalidade de refinar o vocabulário. Após as melhorias propostas na primeira } \\
\text { fase, foram enviados } 12 \text { questionários, a fim de obter-se o grau preliminar de confiabilidade do questionário, } \\
\text { medido pelo alfa de Cronbach. } 0 \text { valor encontrado foi } 0,9643 \text {, o que valida o questionário de pesquisa (Hair } \\
\text { Junior et al., 2005). }\end{array}$ \\
\hline 5. Coletar dados & $\begin{array}{l}\text { Os questionários foram enviados para empresas escolhidas aleatoriamente do banco de dados do } \\
\text { SINDIPEÇAS, via e-mail, juntamente com uma carta convite do pesquisador, no período de agosto a } \\
\text { novembro de } 2012 \text {. Para aumentar a taxa de retorno, antes do envio do e-mail foi realizado contato } \\
\text { telefônico. A pesquisa atingiu um retorno de } 88 \text { questionários }(19,5 \%) \text {, dos quais } 10 \text { foram descartados por } \\
\text { falha de preenchimento, totalizando } 78 \text { questionários válidos }(17,3 \%) \text {. }\end{array}$ \\
\hline 6. Analisar os dados & $\begin{array}{l}\text { A análise de dados é composta das fases estatística descritiva univariada, visando entender o perfil das } \\
\text { empresas, e multivariada, que contempla o tratamento estatístico de análise fatorial, com o objetivo de } \\
\text { determinar os fatores que promovem a GC. } 0 \text { tratamento de dados foi realizado com o auxilio do software } \\
\text { SPSS 21.0. }\end{array}$ \\
\hline $\begin{array}{l}\text { 7. Discutir os dados e } \\
\text { concluir }\end{array}$ & $\begin{array}{l}\text { A partir dos dados coletados e analisados, foram realizadas discussões e feitas conclusões a partir dos } \\
\text { resultados obtidos. }\end{array}$ \\
\hline
\end{tabular}

Fonte: adaptado de Forza (2002).

\section{Objetivo da Análise Fatoria}

(i) Identificação de estrutura de fatores latentes - Análise fatorial tipo $\mathrm{R}$

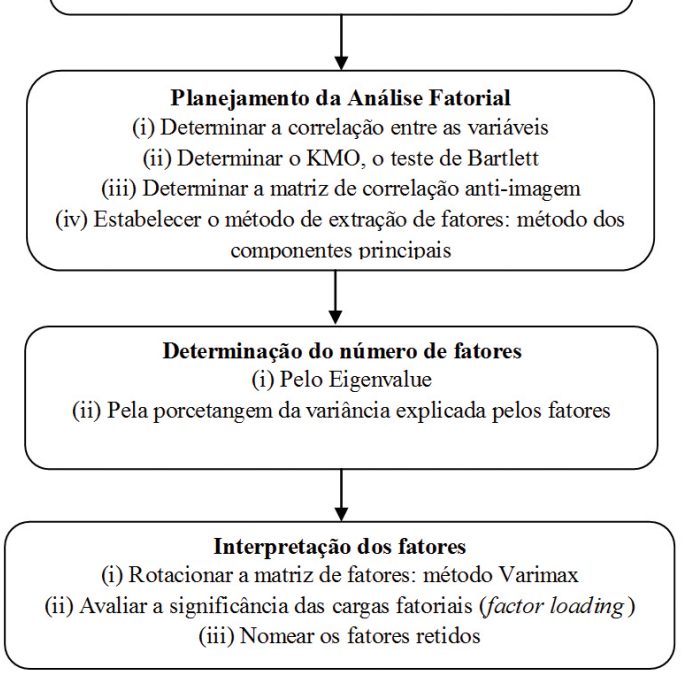

Figura 1. Procedimento da análise fatorial dos dados.

porte, sendo que a grande maioria possui entre 500 e 5 mil funcionários (46\%), 41\% das empresas possuem entre 100 e 500 funcionários e 13\% das empresas possuem mais que 5 mil funcionários.
Em relação ao tempo de atuação das empresas no mercado automobilístico, a empresa pesquisou organizações com pelo menos cinco anos no mercado. Os dados apontam que a maior concentração foi de empresas com tempo de atuação entre 10 e 20 anos (33\%) e com mais de 40 anos no mercado (32\%). 0 número de empresas com tempo entre 5 a 10 anos foi pequeno, cerca de 7,7\%.

0 estudo de fatores contextuais da organização exige que o entrevistado possua uma visão mais aprofundada do contexto organizacional. Assim, foram considerados os níveis hierárquicos de direção, gerência e supervisão, cargos que possuem poder de decisão. Os dados coletados apontam que a maioria dos respondentes é de nível gerencial (53\%), 25\% são supervisores e $22 \%$ são diretores nas funções consideradas pela pesquisa.

\subsection{Análise fatorial exploratória}

0 primeiro passo da análise fatorial constitui uma análise visual da matriz de correlação. Preferencialmente, mais que a metade das correlações deve ser significativa e as correlações entre as variáveis acima de 0,30 são consideradas significantes (Hair Junior et al., 2005). A matriz de correlação resultante 
desta pesquisa indica que 853 das 1.035 correlações, ou $82,4 \%$, são significantes.

0 segundo passo consiste na análise da significância geral de correlação, com o teste de esfericidade de Bartlett (BTS - Bartlett Test of Sphericity), e a consistência dos dados originais, por meio do teste Kaiser-Meyer-Olkin Measure of Sampling Adequacy (KMO), conforme Tabela 7.

Os dados coletados apresentaram um valor satisfatório quanto à adequação da amostra (KMO), pois estão acima de 0,50 (Hair Junior et al., 2005), e a hipótese de matriz identidade foi invalidada pelo teste de Bartlett a um nível de significância de 5\%.

Em seguida são determinados os valores das comunalidades das 46 variáveis da pesquisa. A análise dos valores de comunalidade indica que as variâncias das 46 variáveis são explicadas em mais de $50 \%$ pelos fatores, portanto todas as variáveis são significantes para a constituição deles (Tabela 8).

A etapa seguinte compreende a realização de análise fatorial com a finalidade de obterem-se fatores comuns e a estrutura de correlação entre os fatores e as variáveis. A Tabela 9 apresenta os fatores possiveis de serem extraídos e seus respectivos poderes explanatórios. Aplicando-se o critério da raiz latente, apenas os oito primeiros fatores são mantidos e o poder de explicação da variância dos dados originais por esse modelo é de $81,7 \%$, acima do percentual proposto por Hair Junior et al. (2005) em pesquisas relacionadas às ciências sociais, que propõem uma explicação de pelo menos 60\% da variância por parte dos fatores extraídos.

A Tabela 10 apresenta a matriz de componentes rotacionados a partir do método Varimax. A carga fatorial mínima para a manutenção de uma variável em um determinado fator, em função do tamanho da amostra da pesquisa, é de 0,5 , portanto evidencia-se que todas as variáveis são mantidas em seus respectivos fatores.

A etapa seguinte consiste em nomear os oito fatores retidos em função das variáveis que cada um deles absorveu. A Tabela 11 sumariza a denominação dos oito fatores extraídos bem como as respectivas variáveis que os compõem.

\subsection{Análise}

0 desenvolvimento da pesquisa, realizada em empresas do setor automobilístico, revelou a existência de oito fatores contextuais relevantes para a GC. A Tabela 12 apresenta a relação dos fatores com o processo de GC. Esses fatores constituem o conjunto de requisitos, desenvolvidos no âmbito organizacional
Tabela 7. Valores de KMO e teste de esfericidade de Bartlett.

\begin{tabular}{lcc}
\hline \multicolumn{3}{c}{ KMO e teste de Bartlett } \\
\hline KMO & \multicolumn{3}{c}{0.847} \\
\hline \multirow{3}{*}{ Teste de Bartlett } & $\mathrm{X}^{2}$ & 4555,025 \\
& gl & 1035 \\
& sig. & 0,000 \\
\hline
\end{tabular}

Tabela 8. Comunalidades das 46 variáveis presentes no questionário de pesquisa.

\begin{tabular}{cccccc}
\hline Variável & Inicial & Extração & Variável & Inicial & Extração \\
\hline RH1 & 1 & 0,8892 & TE6 & 1 & 0,8585 \\
RH2 & 1 & 0,8139 & TE7 & 1 & 0,8154 \\
RH3 & 1 & 0,6851 & TE8 & 1 & 0,9106 \\
RH4 & 1 & 0,7786 & E01 & 1 & 0,8129 \\
RH5 & 1 & 0,7293 & E02 & 1 & 0,8123 \\
RH6 & 1 & 0,7780 & E03 & 1 & 0,7520 \\
RH7 & 1 & 0,7652 & E04 & 1 & 0,7888 \\
RH8 & 1 & 0,8371 & E05 & 1 & 0,7613 \\
RH9 & 1 & 0,7758 & E06 & 1 & 0,7762 \\
C01 & 1 & 0,8486 & E07 & 1 & 0,7724 \\
C02 & 1 & 0,7807 & E08 & 1 & 0,8577 \\
C03 & 1 & 0,8021 & E09 & 1 & 0,7251 \\
C04 & 1 & 0,8202 & CAbs1 & 1 & 0,8829 \\
C05 & 1 & 0,7381 & CAbs2 & 1 & 0,8531 \\
C06 & 1 & 0,8903 & CAbs3 & 1 & 0,8323 \\
C07 & 1 & 0,9104 & CAbs4 & 1 & 0,8661 \\
C08 & 1 & 0,7763 & CAbs5 & 1 & 0,8101 \\
C09 & 1 & 0,9082 & CAbs6 & 1 & 0,8215 \\
TE1 & 1 & 0,8469 & CAbs7 & 1 & 0,8550 \\
TE2 & 1 & 0,8795 & CAbs8 & 1 & 0,8468 \\
TE3 & 1 & 0,8070 & CAbs9 & 1 & 0,8587 \\
TE4 & 1 & 0,8237 & CAbs10 & 1 & 0,8130 \\
TE5 & 1 & 0,7916 & CAbs11 & 1 & 0,8237 \\
\hline
\end{tabular}

que se relacionam com o ciclo do conhecimento na organização.

A base para a fase de aquisição e utilização de conhecimentos é o desenvolvimento de competências dos indivíduos, referente ao fator 6, Mapeamento, avaliação e desenvolvimento de competências. Esse fator implica no constante mapeamento das competências centrais para a organização, no desdobramento delas em habilidades e conhecimentos específicos dos funcionários, em um processo de avaliação contínua das habilidades de conhecimentos dominadas pelos funcionários, a fim de planejar e executar um processo de capacitação das pessoas.

A partir de funcionários capacitados em torno de conhecimentos centrais, a organização inicia o processo de construção de sua base de conhecimentos primários retidos, a qual constitui o núcleo central do conhecimento dos indivíduos e facilita o processo de absorção de novos conhecimentos. Sem essa base de conhecimentos primários, os funcionários 
Tabela 9. Fatores extraídos e porcentagem da variância explicada.

\begin{tabular}{|c|c|c|c|c|c|c|c|c|c|}
\hline \multirow{2}{*}{ Componente } & \multicolumn{3}{|c|}{ Eigenvalue inicial } & \multicolumn{3}{|c|}{$\begin{array}{c}\text { Soma dos quadrados dos fatores } \\
\text { extraídos }\end{array}$} & \multicolumn{3}{|c|}{$\begin{array}{c}\text { Soma dos quadrados dos fatores } \\
\text { rotacionados }\end{array}$} \\
\hline & Total & $\begin{array}{c}\text { \% da } \\
\text { variância }\end{array}$ & $\begin{array}{c}\% \\
\text { acumulada }\end{array}$ & Total & $\begin{array}{c}\text { \% da } \\
\text { variância }\end{array}$ & $\begin{array}{c}\% \\
\text { acumulada }\end{array}$ & Total & $\begin{array}{c}\% \text { da } \\
\text { variância }\end{array}$ & $\begin{array}{c}\% \\
\text { acumulada }\end{array}$ \\
\hline 1 & 24,367 & 52,971 & 52,971 & 24,367 & 52,971 & 52,971 & 6,790 & 14,760 & 14,760 \\
\hline 2 & 3,327 & 7,233 & 60,204 & 3,327 & 7,233 & 60,204 & 6,722 & 14,613 & 29,373 \\
\hline 3 & 2,386 & 5,186 & 65,390 & 2,386 & 5,186 & 65,390 & 6,303 & 13,703 & 43,076 \\
\hline 4 & 1,852 & 4,026 & 69,416 & 1,852 & 4,026 & 69,416 & 3,918 & 8,517 & 51,594 \\
\hline 5 & 1,711 & 3,721 & 73,136 & 1,711 & 3,721 & 73,136 & 3,736 & 8,122 & 59,715 \\
\hline 6 & 1,399 & 3,042 & 76,178 & 1,399 & 3,042 & 76,178 & 3,673 & 7,985 & 67,701 \\
\hline 7 & 1,350 & 2,936 & 79,114 & 1,350 & 2,936 & 79,114 & 3,381 & 7,350 & 75,051 \\
\hline 8 & 1,193 & 2,593 & 81,707 & 1,193 & 2,593 & 81,707 & 3,062 & 6,656 & 81,707 \\
\hline 9 & 0,994 & 2,162 & 83,869 & & & & & & \\
\hline 10 & 0,761 & 1,654 & 85,523 & & & & & & \\
\hline 11 & 0,673 & 1,463 & 86,986 & & & & & & \\
\hline 12 & 0,593 & 1,288 & 88,274 & & & & & & \\
\hline 13 & 0,500 & 1,088 & 89,362 & & & & & & \\
\hline 14 & 0,495 & 1,076 & 90,437 & & & & & & \\
\hline 15 & 0,465 & 1,010 & 91,447 & & & & & & \\
\hline 16 & 0,401 & 0,872 & 92,319 & & & & & & \\
\hline 17 & 0,383 & 0,833 & 93,152 & & & & & & \\
\hline 18 & 0,297 & 0,646 & 93,798 & & & & & & \\
\hline 19 & 0,288 & 0,627 & 94,425 & & & & & & \\
\hline 20 & 0,271 & 0,589 & 95,014 & & & & & & \\
\hline 21 & 0,236 & 0,512 & 95,526 & & & & & & \\
\hline 22 & 0,210 & 0,457 & 95,983 & & & & & & \\
\hline 23 & 0,191 & 0,416 & 96,399 & & & & & & \\
\hline 24 & 0,184 & 0,399 & 96,799 & & & & & & \\
\hline 25 & 0,169 & 0,368 & 97,167 & & & & & & \\
\hline 26 & 0,152 & 0,331 & 97,498 & & & & & & \\
\hline 27 & 0,139 & 0,303 & 97,801 & & & & & & \\
\hline 28 & 0,130 & 0,283 & 98,084 & & & & & & \\
\hline 29 & 0,121 & 0,263 & 98,347 & & & & & & \\
\hline 30 & 0,105 & 0,229 & 98,576 & & & & & & \\
\hline 31 & 0,090 & 0,196 & 98,772 & & & & & & \\
\hline 32 & 0,077 & 0,167 & 98,939 & & & & & & \\
\hline 33 & 0,072 & 0,157 & 99,096 & & & & & & \\
\hline 34 & 0,066 & 0,144 & 99,240 & & & & & & \\
\hline 35 & 0,055 & 0,121 & 99,361 & & & & & & \\
\hline 36 & 0,050 & 0,109 & 99,470 & & & & & & \\
\hline 37 & 0,048 & 0,104 & 99,574 & & & & & & \\
\hline 38 & 0,039 & 0,085 & 99,659 & & & & & & \\
\hline 39 & 0,034 & 0,075 & 99,734 & & & & & & \\
\hline 40 & 0,030 & 0,066 & 99,800 & & & & & & \\
\hline 41 & 0,023 & 0,050 & 99,850 & & & & & & \\
\hline 42 & 0,020 & 0,043 & 99,894 & & & & & & \\
\hline 43 & 0,016 & 0,034 & 99,927 & & & & & & \\
\hline 44 & 0,013 & 0,029 & 99,956 & & & & & & \\
\hline 45 & 0,012 & 0,025 & 99,981 & & & & & & \\
\hline 46 & 0,009 & 0,019 & 100,000 & & & & & & \\
\hline
\end{tabular}

Extraction Method: Principal Component Analysis.

não possuem premissas para a aprendizagem explorativa ou explotativa, relacionada à utilização do conhecimento, a qual trará diferencial competitivo à organização. 0 fator 4, denominado Conhecimento primário e identidade compartilhados traz à tona a importância dessa base de conhecimento para o processo de GC. Além disto, o desenvolvimento de conhecimento primário comum está relacionado à formação de uma identidade compartilhada, pois os indivíduos passam a deter uma linguagem e forma 
Gonzalez, R. V. D. et al.

Gestão do conhecimento: uma análise ... fatores contextuais da organização. Production, v. 25, n. 4, p. 834-850, out./dez. 2015

Tabela 10. Matriz de componentes rotacionada (Rotação Varimax).

\begin{tabular}{|c|c|c|c|c|c|c|c|c|}
\hline Variáveis & 1 & 2 & 3 & 4 & 5 & 6 & 7 & 8 \\
\hline $\mathrm{CO} 4$ & 0,7136 & 0,2726 & 0,1626 & 0,4182 & 0,0115 & 0,0770 & $-0,0159$ & 0,1708 \\
\hline $\mathrm{CO5}$ & 0,7327 & 0,3363 & 0,2001 & 0,1366 & $-0,1170$ & 0,0487 & 0,0738 & 0,0899 \\
\hline TE3 & 0,7662 & 0,1897 & 0,2225 & 0,3080 & $-0,0189$ & $-0,0849$ & 0,1748 & 0,0379 \\
\hline E05 & 0,7330 & 0,1673 & 0,3094 & $-0,0606$ & 0,0116 & 0,0906 & 0,2941 & 0,0435 \\
\hline CAbs2 & 0,7337 & 0,1306 & 0,1828 & 0,0631 & 0,1866 & 0,3113 & 0,2081 & 0,2923 \\
\hline CAbs3 & 0,7320 & 0,1524 & 0,2277 & 0,0552 & 0,1980 & 0,1930 & 0,3550 & 0,1265 \\
\hline CAbs6 & 0,7498 & 0,2444 & 0,1996 & 0,0428 & 0,2066 & 0,1780 & 0,2039 & 0,2049 \\
\hline CAbs 10 & 0,7507 & 0,1617 & 0,2752 & 0,0455 & 0,2147 & 0,2159 & 0,1619 & 0,1630 \\
\hline C01 & 0,2329 & 0,6137 & 0,0829 & 0,4876 & 0,2152 & 0,1239 & 0,2869 & 0,1706 \\
\hline $\mathrm{CO} 2$ & 0,2707 & 0,5582 & 0,1621 & 0,3447 & 0,2417 & 0,2856 & 0,1905 & 0,2728 \\
\hline C06 & 0,2173 & 0,7934 & 0,2249 & 0,1844 & 0,0926 & 0,2185 & 0,2262 & 0,1471 \\
\hline $\mathrm{CO} 7$ & 0,2799 & 0,7413 & 0,2500 & 0,2381 & 0,2272 & 0,1966 & 0,0270 & 0,2693 \\
\hline $\mathrm{CO8}$ & 0,2942 & 0,6576 & 0,2543 & 0,1485 & 0,3341 & 0,1528 & 0,1012 & 0,1594 \\
\hline c09 & 0,2573 & 0,7302 & 0,1438 & 0,3231 & 0,1847 & 0,1836 & 0,2121 & 0,2666 \\
\hline TE1 & 0,2519 & 0,7050 & 0,3116 & 0,0828 & 0,2307 & 0,2959 & 0,1788 & 0,0985 \\
\hline TE2 & 0,3313 & 0,6874 & 0,2200 & 0,1543 & 0,3315 & 0,2181 & 0,2052 & 0,1600 \\
\hline TE4 & 0,2386 & 0,6934 & 0,2996 & 0,2397 & 0,1963 & 0,2228 & 0,2140 & 0,0695 \\
\hline $\mathrm{RH} 4$ & 0,2758 & 0,0946 & 0,7079 & 0,2153 & 0,1988 & 0,2111 & 0,2012 & 0,1467 \\
\hline RH5 & 0,2620 & 0,1576 & 0,6541 & 0,2374 & 0,2648 & 0,1518 & 0,1841 & 0,1569 \\
\hline RH6 & 0,3764 & 0,2537 & 0,6558 & 0,1365 & 0,2643 & 0,1972 & $-0,0737$ & 0,0957 \\
\hline RH7 & 0,2864 & 0,2484 & 0,5987 & 0,2423 & 0,4040 & $-0,0284$ & 0,1500 & 0,1340 \\
\hline RH8 & 0,3573 & 0,1387 & 0,6709 & 0,2097 & 0,2330 & 0,3032 & 0,0315 & 0,2210 \\
\hline $\mathrm{RH} 9$ & 0,1394 & 0,2490 & 0,7955 & 0,1530 & 0,1705 & $-0,0768$ & $-0,0549$ & 0,0114 \\
\hline $\mathrm{CO} 3$ & 0,4333 & 0,2295 & 0,6590 & 0,0608 & 0,1812 & 0,1921 & 0,0864 & 0,2157 \\
\hline E01 & 0,0966 & 0,2057 & 0,6050 & 0,2190 & $-0,1471$ & 0,1337 & 0,5072 & 0,2248 \\
\hline E02 & 0,1730 & 0,2304 & 0,7221 & 0,1404 & $-0,1406$ & 0,1447 & 0,3564 & 0,1435 \\
\hline E04 & 0,2995 & 0,0726 & 0,5637 & 0,2486 & $-0,1586$ & 0,2972 & 0,4028 & 0,1966 \\
\hline TE5 & 0,1933 & 0,3519 & 0,3737 & 0,6288 & 0,0917 & 0,2246 & 0,1525 & $-0,1149$ \\
\hline TE6 & 0,2230 & 0,2512 & 0,2512 & 0,7147 & 0,2500 & 0,2003 & 0,0615 & 0,2561 \\
\hline TE7 & 0,0849 & 0,3209 & 0,3572 & 0,7374 & 0,0703 & 0,1628 & $-0,0049$ & 0,0496 \\
\hline TE8 & 0,1242 & 0,1886 & 0,2246 & 0,7731 & 0,2719 & 0,1973 & 0,1524 & 0,2747 \\
\hline CAbs1 & 0,1568 & 0,3929 & 0,1766 & 0,1734 & 0,7246 & 0,1971 & 0,2402 & 0,1457 \\
\hline CAbs4 & 0,1291 & 0,3726 & 0,2534 & 0,1683 & 0,6361 & 0,3209 & 0,1697 & 0,2859 \\
\hline CAbs5 & 0,0052 & 0,4072 & 0,3490 & 0,1639 & 0,5989 & 0,2743 & 0,1735 & 0,1778 \\
\hline CAbs11 & 0,0800 & 0,2680 & 0,1159 & 0,2170 & 0,7795 & 0,2180 & 0,1144 & 0,1298 \\
\hline RH1 & 0,1986 & 0,2902 & 0,2724 & 0,1046 & 0,2284 & 0,7871 & 0,0736 & 0,0583 \\
\hline $\mathrm{RH} 2$ & 0,2183 & 0,2562 & 0,1817 & 0,1717 & 0,1588 & 0,7642 & $-0,0408$ & 0,1651 \\
\hline $\mathrm{RH} 3$ & 0,1705 & 0,3392 & 0,0380 & 0,1950 & 0,1297 & 0,6412 & 0,2284 & 0,1466 \\
\hline E03 & $-0,0029$ & 0,2368 & 0,1622 & 0,4400 & 0,2587 & 0,6052 & 0,1761 & 0,1088 \\
\hline CAbs7 & 0,3897 & 0,2575 & 0,1611 & 0,0365 & 0,1436 & 0,0385 & 0,7659 & $-0,0300$ \\
\hline CAbs8 & 0,3415 & 0,2447 & 0,0744 & 0,1319 & 0,3361 & 0,1135 & 0,7142 & 0,1068 \\
\hline CAbs9 & 0,3239 & 0,2485 & 0,2304 & 0,1015 & 0,2437 & 0,0915 & 0,7321 & 0,1583 \\
\hline E06 & 0,1132 & 0,1838 & 0,2515 & 0,1427 & 0,1198 & 0,0527 & 0,3309 & 0,7207 \\
\hline E07 & 0,3522 & 0,4015 & 0,1764 & 0,2123 & 0,1294 & 0,2496 & $-0,0037$ & 0,5762 \\
\hline E08 & 0,2268 & 0,3143 & 0,2193 & 0,0884 & 0,1490 & 0,0725 & 0,0349 & 0,7893 \\
\hline E09 & 0,3400 & 0,0888 & 0,1044 & 0,1351 & 0,2609 & 0,3849 & $-0,0417$ & 0,5954 \\
\hline
\end{tabular}

de agir homogêneas, facilitando a sua interação e a distribuição do conhecimento.

0 fator 2, Cultura de aprendizagem e trabalho em equipe, está relacionado diretamente à formação de uma identidade compartilhada. A cultura organizacional dita os valores, crenças e a forma de agir dos indivíduos, denotando um grau de identidade entre eles. Os grupos são compostos por indivíduos que compartilham identidade e valores, isto é, atuam sob o mesmo paradigma cultural, explicando a junção dos conceitos cultura de aprendizagem e trabalho em equipe em único fator. A cultura de aprendizagem está relacionada à cooperação entre os indivíduos, à constante troca de experiências e conhecimento, promovendo a distribuição do conhecimento. 0 desenvolvimento 
Tabela 11. Fatores extraídos e variáveis associadas.

\begin{tabular}{|c|c|}
\hline Fator extraído & Variáveis associadas \\
\hline $\begin{array}{l}\text { 1. Resolução de } \\
\text { problemas e Melhoria } \\
\text { incremental }\end{array}$ & $\begin{array}{l}\text { C02. Quando um funcionário apresenta uma ideia ou projeto de melhoria existe a cooperação dos demais colegas } \\
\text { CO3. Quando um funcionário apresenta uma ideia ou projeto de melhoria existe o reconhecimento de seu superior } \\
\text { TE3. A empresa oferece aos funcionários autonomia para resolverem problemas operacionais } \\
\text { E05. É comum diversos projetos ou atividades envolverem simultaneamente dois ou mais setores da empresa } \\
\text { CAbs2. O conhecimento desenvolvido pelos funcionários é utilizado em atividades de melhoria } \\
\text { CAbs3. A utilização do conhecimento e das competências,adquiridos ao longo do tempo mantém a empresa } \\
\text { competitiva frente aos concorrentes } \\
\text { CAbs6. Os processos e atividade praticados rotineiramente evoluem com o tempo } \\
\text { CAbs10. A empresa possui um método estruturado para solução de problemas (procedimento, utilização de } \\
\text { ferramentas, formação de equipes etc.) }\end{array}$ \\
\hline $\begin{array}{l}\text { 2. Cultura de } \\
\text { aprendizagem e } \\
\text { Trabalho em equipe }\end{array}$ & $\begin{array}{l}\text { C01. Os funcionários costumam trocar informações e experiências quando se deparam com um problema } \\
\text { CO2. Após seções de treinamento, os funcionários interagem sobre os conhecimentos adquiridos } \\
\text { C06. Existe uma comunicação constante entre funcionários e gerência sobre a situação da empresa } \\
\text { C07. A empresa apresenta uma cultura que estimula seus funcionários a tomarem decisões e assumirem riscos } \\
\text { inerentes aos seus processos } \\
\text { C08. A empresa interpreta eventuais erros cometidos pelos funcionários como parte do processo de aprendizagem } \\
\text { C09. Os gestores da empresa conseguem identificar as melhores práticas nos processos pelos quais são } \\
\text { responsáveis } \\
\text { TE1. Os projetos de trabalho são realizados, em sua maioria, em grupos que executam e analisam conjuntamente } \\
\text { os resultados } \\
\text { TE2. A empresa incentiva o aprendizado e a troca de informações entre os funcionários } \\
\text { TE4. A organização estimula a interação entre funcionários de diferentes especialidades }\end{array}$ \\
\hline $\begin{array}{l}\text { 3. Postura proativa e } \\
\text { Estrutura organizacional } \\
\text { enxuta }\end{array}$ & $\begin{array}{l}\text { RH4. Os profissionais da empresa buscam o autodesenvolvimento } \\
\text { RH5. Os profissionais da empresa estão capacitados a tomarem decisões e gerenciarem riscos } \\
\text { RH6. A empresa apresenta mecanismos de premiação e recompensas por resultados atingidos } \\
\text { RH7. Os funcionários reconhecem a importância de seu trabalho em relação à estratégia da empresa } \\
\text { RH8. O processo de recrutamento valoriza a postura criativa e o espirito empreendedor } \\
\text { RH9. Os funcionários são altamente polivalentes, isto é, exercem diversas funções relativas aos seus processos de } \\
\text { trabalho } \\
\text { E01. A empresa possui poucos niveis hierárquicos, isto é, verticalmente, ela apresenta uma estrutura enxuta } \\
\text { E02. Existe facilidade de comunicação entre os setores ou departamentos da empresa } \\
\text { E04. A empresa consegue mudar quando necessário a estrutura de departamentos, cargos e atribuições }\end{array}$ \\
\hline $\begin{array}{l}\text { 4. Conhecimento } \\
\text { primário e identidade } \\
\text { compartilhados }\end{array}$ & $\begin{array}{l}\text { TE5. Os funcionários de um determinado setor ou grupo criam uma linguagem comum entre eles, relativa ao } \\
\text { processo de trabalho } \\
\text { TE6. Os funcionários dos grupos de trabalho têm a capacidade de se autogerenciarem, isto é, capacidade de auto- } \\
\text { organização } \\
\text { TE7. É perceptível que os funcionários de um determinado setor ou grupo de trabalho sentem-se "donos" daquela } \\
\text { área } \\
\text { TE8. Os funcionários de um grupo têm ciência dos conhecimentos e habilidades dominadas por seus colegas de } \\
\text { trabalho }\end{array}$ \\
\hline $\begin{array}{l}\text { 5. Capacidade } \\
\text { de absorção de } \\
\text { conhecimento }\end{array}$ & $\begin{array}{l}\text { CAbs1. A empresa desenvolve novas tecnologias internamente } \\
\text { CAbs4. A empresa tem fácil acesso a novas tecnologias (originadas de especialistas externos, de universidades, } \\
\text { parceria com outras empresas etc.) } \\
\text { CAbs5. A empresa tem facilidade em aplicar novas tecnologias e conhecimentos } \\
\text { CAbs11. A empresa adquire novos conhecimentos por meio de aquisição de patentes ou em parceria com outras } \\
\text { organizações }\end{array}$ \\
\hline $\begin{array}{l}\text { 6. Mapeamento } \\
\text { e avaliação de } \\
\text { competências }\end{array}$ & $\begin{array}{l}\text { RH1. A empresa possui um método estruturado para a avaliação das competências exigidas dos funcionários } \\
\text { RH2. Os gestores acompanham e avaliam constantemente o desenvolvimento de seus subordinados } \\
\text { RH3. A empresa oferece cursos/palestras aos funcionários, para o aprimoramento das competências } \\
\text { E03. Existe um grande interesse da organização em estabelecer procedimentos, métodos ou instruções para as } \\
\text { atividades }\end{array}$ \\
\hline 7. Estratégia inovativa & $\begin{array}{l}\text { CAbs7. A empresa domina a tecnologia envolvida em sua área de atuação } \\
\text { CAbs8. A empresa antecipa inovações no mercado em que concorre } \\
\text { CAbs9. As competências desenvolvidas internamente facilitam à empresa explorar novas oportunidades no } \\
\text { mercado }\end{array}$ \\
\hline $\begin{array}{l}\text { 8. Sistema de } \\
\text { informação }\end{array}$ & $\begin{array}{l}\text { E06. Os Sls da sua empresa estão integrados, sendo possível que qualquer área da empresa tenha acesso ao } \\
\text { conteúdo das demais } \\
\text { E07. As melhores práticas de cada departamento são registradas em um banco de dados } \\
\text { E08. Existe amplo acesso ao banco de dados da empresa, independentemente do nível hierárquico do funcionário } \\
\text { E09. A empresa apresenta ambientes virtuais para discussão entre os funcionários (fóruns virtuais, grupos de } \\
\text { e-mails, MSN, entre outros) }\end{array}$ \\
\hline
\end{tabular}

de uma cultura que fomente a descoberta de novos conhecimentos, o processo de tentativa e erro, experimentação e pesquisa, aliado à organização de trabalhos em grupo, que valorizem a interação multidisciplinar dos indivíduos, são características organizacionais que favorecem a aquisição e utilização de conhecimento. Em relação ao processo de armazenamento do conhecimento, os grupos de trabalho retêm conhecimento tácito, uma vez que eles desenvolvem um conjunto de habilidades e formas de agir peculiar a cada equipe, que facilita as interações e o diálogo entre os indivíduos. 
Tabela 12. Fatores contextuais da organização e o processo de GC.

\begin{tabular}{|c|c|c|}
\hline Fator & Processo de GC & Justificativa \\
\hline $\begin{array}{l}\text { 1. Resolução de problemas } \\
\text { e melhoria incremental }\end{array}$ & $\begin{array}{l}\text { - Aquisição } \\
\text { - Utilização }\end{array}$ & $\begin{array}{l}\text { Essas duas atividades, resolução de problemas e melhoria incremental, constituem formas } \\
\text { de explotação do conhecimento (Cohen \& Levinthal, 1990), caracterizando um processo } \\
\text { de aquisição do conhecimento. Além disso, a explotação constitui um processo de } \\
\text { aprendizagem dos indivíduos no qual novos conhecimentos são utilizados (Crossan et al., } \\
\text { 1999). }\end{array}$ \\
\hline $\begin{array}{l}\text { 2. Cultura de } \\
\text { aprendizagem e trabalho } \\
\text { em equipe }\end{array}$ & $\begin{array}{l}\text { - Aquisição } \\
\text { - Armazenamento } \\
\text { - Distribuição } \\
\text { - Utilização }\end{array}$ & $\begin{array}{l}\text { Esse fator associa-se à aquisição, pois a cultura de aprendizagem é baseada no estímulo } \\
\text { à experimentação, favorecendo a criação de novos conhecimentos (Skerlavaj et al., } \\
\text { 2007; Gold et al., 2001); à distribuição, pois a cultura de aprendizagem é voltada à } \\
\text { disseminação do conhecimento em grupos (Rowley, 2001); ao armazenamento, uma vez } \\
\text { que os grupos de trabalho retêm um conhecimento tácito; e à utilização, por meio da } \\
\text { fomentação do processo de tentativa e erro (lrani et al., 2009). }\end{array}$ \\
\hline $\begin{array}{l}\text { 3. Postura proativa e } \\
\text { estrutura organizacional } \\
\text { enxuta }\end{array}$ & $\begin{array}{l}\text { - Aquisição } \\
\text { - Distribuição } \\
\text { - Utilização }\end{array}$ & $\begin{array}{l}\text { A postura de assumir riscos e tomar decisões dos indivíduos, aliada a uma estrutura } \\
\text { que conceda autonomia aos funcionários, estimula a aquisição e a utilização de } \\
\text { conhecimento, especialmente no que tange à resolução de problemas (Nonaka \& } \\
\text { Takeuchi, 1995). A estrutura organizacional enxuta também facilita a comunicação e } \\
\text { interação entre indivíduos, promovendo a distribuição do conhecimento (Wilkinson \& } \\
\text { Young, 2006; Andrews \& Kacmar 2001). }\end{array}$ \\
\hline $\begin{array}{l}\text { 4. Conhecimento } \\
\text { primário e identidade } \\
\text { compartilhados }\end{array}$ & $\begin{array}{l}\text { - Aquisição } \\
\text { - Armazenamento } \\
\text { - Distribuição } \\
\text { - Utilização }\end{array}$ & $\begin{array}{l}\text { Esse fator associa-se à aquisição e à utilização, pois é a partir do conhecimento } \\
\text { primário que novos conhecimentos podem ser explotados ou explorados (March, 1991; } \\
\text { Rowley, 2001). Também relaciona-se ao armazenamento e distribuição, uma vez que o } \\
\text { conhecimento primário é um conhecimento retido que facilita a comunicação entre os } \\
\text { indivíduos. Além disso, a identidade compartilhada entre os indivíduos gera uma relação } \\
\text { de confiança que estimula o compartilhamento (Brown \& Duguid, 2001). }\end{array}$ \\
\hline $\begin{array}{l}\text { 5. Capacidade de absorção } \\
\text { de conhecimento }\end{array}$ & - Aquisição & $\begin{array}{l}\text { A aquisição está associada à capacidade de a organização absorver conhecimento de } \\
\text { forma explorativa ou explotativa (March, 2001). }\end{array}$ \\
\hline $\begin{array}{l}\text { 6. Mapeamento, avaliação } \\
\text { e desenvolvimento de } \\
\text { competências }\end{array}$ & $\begin{array}{l}\text { - Aquisição } \\
\text { - Armazenamento } \\
\text { - Utilização }\end{array}$ & $\begin{array}{l}\text { Esse fator associa-se à aquisição, pois as competências e a capacidade cognitiva dos } \\
\text { RHs estimulam o processo criativo (Zangiski et al., 2013; Leonard-Barton, 1992); ao } \\
\text { armazenamento, pois são os indivíduos os agentes de retenção do conhecimento tácito } \\
\text { (Zarifian, 2001); e, ainda, à utilização, pois a competência refere-se à capacidade de os } \\
\text { indivíduos utilizarem o conhecimento em situações práticas (Zarifian, 2001). }\end{array}$ \\
\hline 7. Estratégia inovativa & $\begin{array}{l}\text { - Aquisição } \\
\text { - Utilização }\end{array}$ & $\begin{array}{l}\text { A estratégia inovativa tem interesse em adquirir novos conhecimentos a fim de } \\
\text { reconstruir as competências internas, utilizando-as como fonte de diferencial competitivo } \\
\text { (Teece et al., 1997; Volberda et al., 2010). }\end{array}$ \\
\hline 8. Sistema de informação & $\begin{array}{l}\text { - Armazenamento } \\
\text { - Distribuição }\end{array}$ & $\begin{array}{l}\text { Os Sls são ferramentas que possibilitam a retenção e distribuição do conhecimento } \\
\text { explícito (Faraj et al., 2011). }\end{array}$ \\
\hline
\end{tabular}

0 fator 5, Capacidade de absorção de conhecimento, refere-se à capacidade organizacional de adquirir conhecimentos até então não dominados. 0 processo de absorção de conhecimento é bastante dependente da criação de uma base de conhecimento primário (March, 1991; Volberda et al., 2010), sendo essencial para a manutenção e aumento da competitividade da organização. Sem o desenvolvimento de conhecimento primário, a organização não se habilita a aprender novos conhecimentos, tornando-se obsoleta. 0 processo de absorção de conhecimento externo pode ocorrer via interações intraorganizacionais, contratação de funcionários com competências complementares às existentes, aquisição de patentes ou mesmo seções de treinamento. Dessa forma, é fundamental para as organizações buscar a constante capacitação de seus funcionários, construindo uma base sólida de conhecimento primário que promova a absorção dessas diversas fontes de conhecimento externo.

A Estratégia inovativa é o sétimo fator identificado nesta pesquisa como sustentador do processo de $\mathrm{GC}$, estando diretamente relacionado ao processo de aquisição e utilização do conhecimento, uma vez que inovar implica em reconstruir competências e utilizá-las com o intuito de obter vantagem competitiva. Estratégia pode ser definida como forma de competir de uma organização em seu mercado. Assim, uma estratégia inovadora pode ser considerada importante para a GC, pois implica na descoberta de novos conhecimentos por meio de um processo de pesquisa e experimentação.

Da mesma forma que a estratégia inovativa, o fator 1, Resolução de problemas e melhoria incremental, implica num processo de aquisição e utilização de conhecimento. Entretanto, enquanto na estratégia inovativa a ênfase da organização é na busca de novos conhecimentos que permitam a diferenciação, a resolução de problemas e a melhoria incremental têm como foco o refinamento da mesma base de conhecimento. As iniciativas organizacionais voltadas à melhoria contínua podem ser consideradas formas de as organizações aprimorarem constantemente suas bases de conhecimento primário por meio da ampla participação dos funcionários.

Dessa forma, nas organizações com menor capacidade de inovar e absorver conhecimento, os processos de aquisição e utilização da GC são voltados à explotação do conhecimento. Nas empresas mais 
inovadoras, os processos de aquisição e utilização vão além da explotação, abrangendo a exploração do conhecimento, o que implica na prática de atividades de pesquisa e desenvolvimento. As organizações mais inovadoras são aquelas com interesse maior no desenvolvimento de conhecimento primário, aprendizagem em grupo e utilização de sistemas de informação, evidenciando que os processos de armazenamento e distribuição, tanto do conhecimento explícito, por meio de tecnologias de informação, quanto do conhecimento tácito, através de atividades em grupo, ocorrem de forma mais intensa.

0 fator 3 , relacionado à postura proativa e estrutura organizacional enxuta, refere-se à forma de agir dos funcionários em decorrência de um modelo organizacional adotado. Quando expostos a ambientes organizacionais com estruturas verticalmente mais enxutas, os funcionários tendem a desenvolver maior compreensão acerca de seu mercado, bem como dos pontos fortes e fracos da organização, estimulando o processo de geração de novos conhecimentos por meio de atividades de resolução de problemas, melhoria incremental, num sentido explotativo e, também, via pesquisa de novos conhecimentos, em uma perspectiva de aprendizagem explorativa. As estruturas mais enxutas favorecem também a integração interfuncional dos indivíduos, favorecendo a distribuição do conhecimento e também a multidisciplinaridade, que apoia, por sua vez, o processo de aquisição e utilização do conhecimento.

E, por fim, o fator Sistema de informação está intimamente relacionado aos processos de armazenamento e distribuição do conhecimento explícito. Dessa forma, o Sl pode ser considerado uma ferramenta de suporte à GC que facilita o fluxo de informação entre os diversos departamentos e setores da organização.

\section{Conclusões}

Este artigo cumpre seu objetivo de identificar os fatores contextuais que sustentam a prática da $\mathrm{GC}$ no âmbito organizacional. Conforme referências supracitadas, quando uma organização introduz um processo para GC sem que haja uma preparação prévia os resultados acabam sendo frustrantes. Nesse sentido, a identificação desses fatores elucida quais são os pontos que as organizações do setor automobilístico devem enfatizar para que as iniciativas em torno das quatro etapas do processo de GC (aquisição, armazenamento, distribuição e utilização do conhecimento) tragam os resultados esperados.

Para definir a estrutura de fatores latentes que sustentam a GC nas empresas do setor automobilístico, este trabalho partiu do levantamento do referencial teórico sobre cada fase do processo de $\mathrm{GC}$, a fim de compreender as características organizacionais que se relacionam com elas, estabelecendo constructos (desenvolvimento de recursos humanos, cultura organizacional, trabalho em equipe, estrutura organizacional e desenvolvimento e absorção de conhecimento). Esses constructos foram explorados e desdobrados em variáveis de pesquisa e elas, por sua vez, reduzidas a fatores contextuais.

A partir da amostra de 78 empresas do setor automobilístico estudadas foram definidos oito fatores contextuais que sustentam a GC no ambiente organizacional. 0 primeiro, denominado resolução de problemas e melhoria incremental, trata da aprendizagem explotativa, essencialmente, da ação dos indivíduos em ações que visam à resolução de problemas de processos produtivos. Cultura de aprendizagem e trabalho em equipe foi o segundo fator encontrado, o qual considera a importância da criação de um contexto organizacional voltado à experimentação e compartilhamento do conhecimento adquirido. Postura proativa e estrutura organizacional enxuta representa o terceiro fator, que traz à tona a importância de um menor nível de centralização do poder e que pressupõe mais proatividade por parte dos indivíduos e maior nível de integração dos funcionários, favorecendo o trabalho multidisciplinar e o fluxo de conhecimento.

O quarto fator, conhecimento primário e identidade compartilhados, ressalta a importância de as organizações desenvolverem em seus funcionários uma base de conhecimento primário que promova a absorção de novos conhecimentos e, ainda, a importância do senso de identidade dos indivíduos, favorecendo o trabalho em grupo e estimulando a disseminação do conhecimento. Capacidade de absorção de conhecimento foi o quinto fator extraído da análise fatorial - refere-se ao processo de aquisição de conhecimento originado em âmbito interno de atividade como pesquisa e desenvolvimento, ou em âmbito externo, como parcerias, consultorias, contatos com universidades, entre outros. Vale ressaltar que a capacidade de absorção de conhecimento é amparada pelo conhecimento primário organizacional. Sem essa base de conhecimento as organizações têm dificuldades para absorver conhecimentos, comprometendo a competitividade.

O sexto fator, mapeamento, avaliação e desenvolvimento de competências, pode ser considerado um elemento central para o processo de GC. 0 conhecimento é manifestado pela ação do ser humano em atividades práticas, dessa forma, para que o conhecimento possa ser criado e disseminado 
na organização, é necessário o desenvolvimento das competências dos indivíduos.

Estratégia inovativa corresponde ao sétimo fator, referindo-se à forma como a organização se posiciona no mercado e influenciando o modo como o conhecimento é utilizado pela organização. Assim, se a organização adota uma estratégia mais ofensiva, o conhecimento é utilizado com o objetivo de diferenciação e inovação; em contrapartida, se a organização adota como estratégia seguir o desenvolvimento ditado por outras empresas, o conhecimento é utilizado com a finalidade de melhorar a eficiência do processo produtivo.

Sistema de informação é o último fator estabelecido, relaciona-se com o processo de integração do conhecimento. Esse fator trata da utilização de ferramentas de $\mathrm{Tl}$ que promovam a codificação do conhecimento explícito, constituído pelos procedimentos, instruções e melhores práticas relacionados à rotina da organização, facilitando a retenção e distribuição do conhecimento.

Os fatores identificados mostram que o processo de $\mathrm{GC}$ possui dois elementos centrais. 0 primeiro é o ser humano, agente responsável por reter e transformar o conhecimento primário por meio de iniciativas de melhoria e inovação. 0 desenvolvimento de suas competências aumenta a base de conhecimento primário e, consequentemente, a capacidade de absorver novos conhecimentos e a cumulatividade. Além disso, os aspectos motivacionais, como sistemas de premiação e recompensa, são importantes, a fim de desenvolver um maior interesse pelo trabalho por parte dos indivíduos, estimulando uma postura proativa no que tange à tomada de decisão e à resolução de problemas.

0 segundo elemento central do processo de GC diz respeito ao contexto organizacional, que deve ser regido por uma cultura que estimule o processo de aprendizagem, como ações do tipo tentativa e erro e de experimentação. A cultura deve fomentar o senso de cooperação entre os indivíduos a fim de estimular-se o processo de GC. 0 desenvolvimento do trabalho em equipe, especialmente aquele voltado à resolução de problemas, é um fator que favorece a aprendizagem e a distribuição do conhecimento.

A estrutura é outro fator referente ao contexto organizacional que impacta o processo de GC. Estruturas com divisões departamentais mais rígidas e níveis hierárquicos mais densos são menos propícias ao desenvolvimento e distribuição de conhecimento, embora possam ser positivas quanto à utilização do conhecimento formalizado retido em situações de alta repetição. Estruturas mais flexíveis, que possibilitam o fluxo da informação e do conhecimento entre suas fronteiras e favoreçam a formação de grupos interdisciplinares são mais favoráveis à geração e distribuição do conhecimento. Os Sls são elementos de suporte que apoiam especialmente a intensificação do fluxo de conhecimento explícito entre indivíduos.

A vantagem competitiva, objetivo final da $\mathrm{GC}$, é resultado da interação entre indivíduo e desenvolvimento organizacional. Essa vantagem competitiva consiste na capacidade da organização e de seus funcionários aprenderem e absorverem novos conhecimentos a fim de aplicá-los em inovações, apoiando uma estratégia inovativa, bem como em atividades de resolução de problemas e melhorias incrementais.

\section{Referências}

Alavi, M., \& Leidner, D. E. (2001). Management and knowledge management systems: conceptual foundations and research issues. MIS Quarterly, 25(1), 107-136. http:// dx.doi.org/10.2307/3250961

Alvesson, M., \& Kärreman, D. (2001). Odd couple: making sense of the curious concept of knowledge management. Journal of Management Studies, 38(7), 995-1018. http://dx.doi.org/10.1111/1467-6486.00269

Amayah, A. T. (2013). Determinants of knowledge sharing in a public sector organization. Journal of Knowledge Management, 17(3), 454-471. http://dx.doi.org/10.1108/ JKM-11-2012-0369

Andrews, M. C., \& Kacmar, K. M. (2001). Discriminating among organizational politics, justice, and support. Journal of Organization Behavior, 22(4), 347-66. http:// dx.doi.org/10.1002/job.92

Associação Nacional dos Fabricantes de Veículos Automotores - ANFAVEA. (2012). Anuário estatístico da indústria automotiva brasileira. Recuperado em 16 de maio de 2013, de http:// www.anfavea.com.br

Argote, L., Mcevily, B., \& Reagans, R. (2003). Managing knowledge in organizations: an integrative framework and review of emerging themes. Management Science, 49(4), 571-582. http://dx.doi.org/10.1287/ mnsc.49.4.571.14424

Argyris, C., \& Schön, D. (1978). Organizational learning: a theory of action perspective. Boston: Addison-Wesley.

Brown, J. S., \& Duguid, P. (2001). Knowledge and organization: a social-practice perspective. Organization Science, 12(2), 198-213. http://dx.doi.org/10.1287/ orsc.12.2.198.10116

Bryman, A. (1989). Research methods and organization studies. London: Unwin Hyman. http://dx.doi. org/10.4324/9780203359648

Carlile, P. R., \& Rebentisch, E. S. (2003). Into the black box: the knowledge transformation cycle. Management Science, 49(9), 1180-1195. http://dx.doi.org/10.1287/ mnsc.49.9.1180.16564

Chen, C. J., \& Huang, J. W. (2007). How organizational climate and structure affect knowledge management: the social interaction perspective. International Journal of Information Management, 27(2), 104-118. http:// dx.doi.org/10.1016/j.jinfomgt.2006.11.001 
Chen, C. J., Huang, J. W., \& Siao, Y. C. (2010). Knowledge management and innovativeness: the role of organizational climate and structure. International Journal of Manpower, 31(8), 848-870. http://dx.doi. org/10.1108/01437721011088548

Choo, C. W. (1998). The knowing organization: how organizations use information for construct meaning, create knowledge and make decisions. New York: Oxford Press.

Cohen, W. M., \& Levinthal, D. A. (1990). Absorptive capacity: a new perspective on learning and innovation. Administrative Science Quarterly, 35, 128-152. http:// dx.doi.org/10.2307/2393553

Cormican, K., \& 0'Sullivan, D. A. (2003). Collaborative knowledge management tool for product innovation management. International Journal of Technology Management, 26(1), 53-68. http://dx.doi.org/10.1504/ 1JTM.2003.003144

Cross, R., \& Sproull, L. (2004). More than an answer: Information relationships for actionable knowledge. Organization Science, 15(4), 446-462. http://dx.doi. org/10.1287/orsc. 1040.0075

Crossan, M., Lane, H. W., \& White, R. E. (1999). An organizational learning framework: from intuition to institution. Academy of Management Review, 24(3), 522537.

Davenport, T. H., \& Prusak, L. (1998). Conhecimento empresarial: como as organizações gerenciam o seu capital intelectual. Rio de Janeiro: Campus.

De Long, D. W., \& Fahey, L. (2000). Diagnosing cultural barriers to knowledge management. Academy of Management Executive, 14(4), 113-127.

Dibella, A. J., Nevis, E. C., \& Gould, J. M. (1996). Understanding organizational learning capability. Journal of Management Studies, 33(3), 361-379. http:// dx.doi.org/10.1111/j.1467-6486.1996.tb00806.x

Durst, S., \& Edvardsson, 1. R. (2012). Knowledge management in SMEs: a literature review. Journal of Knowledge Management, 16(6), 879-903. http://dx.doi. org/10.1108/13673271211276173

Eisenhardt, K. M. (1989). Making fast strategic decisions in high-velocity environments. Academy Management Journal, 32(3), 543-576. http://dx.doi. org/10.2307/256434

Eisenhardt, K. M., \& Martin, J. A. (2000). Dynamic capabilities: what are they? Strategic Management Journal, 21(10), 1105$1121 . \quad \mathrm{http}: / / \mathrm{dx}$. doi.org/10.1002/1097$0266(200010 / 11) 21: 10 / 11<1105::$ AlD SMJ133>3.0.CO;2-E

Faraj, S., Sirkka, L. J., \& Majchrzak, A. (2011). Knowledge collaboration in online communities. Organization Science, 22(5), 1224-1239. http://dx.doi.org/10.1287/ orsc. 1100.0614

Figueiredo, S. P. (2005). Gestão do conhecimento: estratégias competitivas para a criação e mobilização do conhecimento na empresa. Rio de Janeiro: Qualitymark.

Fleury, A. C. C., \& Fleury, M. T. L. (2000). Estratégias empresariais e formação de competências. São Paulo: Atlas.

Forza, C. (2002). Survey research in operations management: a process-based perspective. International Journal of
Operations \& Production Management, 22(2), 152-194. http://dx.doi.org/10.1108/01443570210414310

Garicano, L., \& Wu, Y. (2012). Knowledge, communication, and organizational capabilities. Organization Science, 23(5), 1382-1397. http://dx.doi.org/10.1287/ orsc. 1110.0723

Gilson, L. L., \& Shalley, C. E. (2004). A little creativity goes a long way: an examination of teams' engagement in creative processes. Journal of Management, 30(4), 45370. http://dx.doi.org/10.1016/j.jm.2003.07.001

Gold, A. H., Malhotra, A., \& Segars, A. H. (2001). Knowledge management: an organizational capabilities perspective. Journal of Management Information Systems, 18(1), 184214.

Grant, R. M. (1996). Toward a knowledge-based theory of the firm. Strategic Management Journal, 17, 109-122.

Gupta, A. K. V., \& Govindarajan, V. (2000). Knowledge flows within multinational corporations. Strategic Management Journal, 21(4), 473-496. http://dx.doi. org/10.1002/(SICl)1097-0266(200004)21:4<473::AIDSMJ84>3.0.CO;2-1

Hair Junior, J. F., Anderson, R. E., Tatham, R. L., \& Black, W. C. (2005). Multivariate data analysis. New Jersey: Prentice Hall.

Huber, G. (1991). Organizational learning the contributing processes and the literatures. Organizational Science, 2(1), 88-115. http://dx.doi.org/10.1287/ orsc.2.1.88

Irani, Z., Sharif, A. M., \& Love, P. E. D. (2009). Mapping knowledge management and organizational learning in support of organizational memory. International Journal of Production Economics, 122, 200-215. http://dx.doi. org/10.1016/j.ijpe.2009.05.020

Janz, B. D., \& Prasarnphnich, P. (2003). Understanding the antecedents of effective knowledge management: the importance of a knowledge-centered culture. Decision Sciences, 34(2), 351-384. http://dx.doi. org/10.1111/1540-5915.02328

Kane, G. C., \& Alavi, M. (2007). Information technology and organizational learning: an investigation of exploration and explotation process. Organization Science, 18(5), 796-812. http://dx.doi.org/10.1287/ orsc. 1070.0286

Lee, P. K. C., To, W. M., \& Ty, B. T. W. (2013). Team attributes and performance of operational service teams: An empirical taxonomy development. International Journal of Production Economics, 142, 51-60. http://dx.doi. org/10.1016/j.ijpe.2012.05.005

Lee, C., \& Yang, J. (2000). Knowledge value chain. The Journal of Management Development, 19(9), 783-794. http://dx.doi.org/10.1108/02621710010378228

Leidner, D. E., \& Elam, J. J. (1995). The impact of executive information systems on organization design, intelligence, and decision making. Organization Science, 6(6), 645664. http://dx.doi.org/10.1287/orsc.6.6.645

Leonard-Barton, D. (1992). The factory as a learning laboratory. Sloan Management Review, 34, (1), 23-38.

Levinthal, D. A., \& March, J. G. (1993). The myopia of learning. Strategic Management Journal, 14, 95-112. http://dx.doi.org/10.1002/smj.4250141009

Liao, C., Chuang, S. H., \& To, P. L. (2011). How knowledge management mediates relationship between environment 
and organizational structure. Journal of Business Research, 64, 728-736. http://dx.doi.org/10.1016/j. jbusres.2010.08.001

Lin, H. F. (2007). A stage model of knowledge management: an empirical investigation of process and effectiveness. Journal of Information Science, 33(6), 643-659. http:// dx.doi.org/10.1177/0165551506076395

London, M., \& Sessa, V. 1. (2007). How groups learn, continuously. Human Resource Management, 46(4), 651669. http://dx.doi.org/10.1002/hrm.20186

Lytras, M., \& Pouloudi, A. (2006). Towards the development of a novel taxonomy of knowledge management systems from a learning perspective: an integrated approach to learning and knowledge infrastructures. Journal of Knowledge Management, 10(6), 64-80. http://dx.doi. org/10.1108/13673270610709224

March, J. G. (1991). Exploration and exploitation in organizational learning. Organization Science, 20(1), 71 87. http://dx.doi.org/10.1287/orsc.2.1.71

Morgan, G. (1996). Imagens da organização. São Paulo: Atlas.

Nelson, R., \& Winter, S. (1982). An evolutionary theory of economic change. Cambridge: Belknap Press/Harvard University Press.

Nonaka, l., \& Takeuchi, H. (1995). The knowledge-creating company. New York: Oxford University Press.

Okhuysen, G. A., \& Eisenhardt, K. M. (2002). Integrating knowledge in groups: how formal interventions enable flexibility. Organization Science, 13(4), 370-386. http:// dx.doi.org/10.1287/orsc. 13.4.370.2947

Orlikowski, W. J. (2002). Knowing in practice: Enacting a collective capability in distributed organizing. Organization Science, 13(3), 249-273. http://dx.doi. org/10.1287/orsc.13.3.249.2776

Ostroff, F. (1999). The horizontal organization. New York: Oxford University Press.

Prajogo, D. 1., \& McDermott, C. M. (2011). The relationship between multidimensional organizational culture and performance. International Journal of Operations \& Productions Management, 31(7), 712-735. http://dx.doi. org/10.1108/01443571111144823

Quigley, N. R., Tesluk, P. E., Locke, E. A., \& Bartol, K. M. (2007). A multilevel investigation of the motivational mechanisms underlying knowledge sharing and performance. Organization Science, 18(1), 71-88. http:// dx.doi.org/10.1287/orsc.1060.0223

Rowley, J. (2001). Knowledge management in pursuit of learning: the learning with knowledge cycle. Journal of Information Science, 27(4), 227-237. http://dx.doi. org/10.1177/016555150102700406

Schuring, R. W. (1996). Operational autonomy explains the value of group work in both lean and reflective production. International Journal of Operations \& Production Management, 16(2), 171-182. http://dx.doi. org/10.1108/01443579610197120

Skerlavaj, M., Stenberger, M. 1., Skrinjar, R., \& Dimovski, V. (2007). Organizational learning culture: the missing link between business process change and organizational performance. International Journal of Production Economics, 106, 346-367. http://dx.doi.org/10.1016/j. ijpe.2006.07.009
Stewart, T. A. (1998). Capital intelectual. Rio de Janeiro: Campus.

Sveiby, K. E. (1997). A nova riqueza das organizações: gerenciando e avaliando patrimônios de conhecimento. Rio de Janeiro: Campus.

Tanskanen, T., Buhanist, P., \& Kostama, H. (1998). Exploring the diversity of teams. International Journal of Production Economics, 56-57, 611-619. http://dx.doi. org/10.1016/S0925-5273(96)00097-7

Teece, D. J., Pisano, A., \& Shuen, A. (1997). Dynamic capabilities and strategic management. Strategic Management Journal, 18(7), 509-533. http://dx.doi. org/10.1002/(SICl) 1097-0266(199708)18:7<509::AIDSMJ882>3.0.CO;2-Z

Teece, D. J. (2007). Explicating dynamic capabilities: the nature and microfondations of (sustainable) entreprise performance. Strategic Management Journal, 28(13), 1319-1350. http://dx.doi.org/10.1002/smj.640

Turner, J. R., Zimmerman, T., \& Allen, J. M. (2012). Teams as a sub-process for knowledge management. Journal of Knowledge Management, 16(6), 963-977. http://dx.doi. org/10.1108/13673271211276227

Volberda, H. W., Foss, N. J., \& Lyles, M. A. (2010). Absorbing the concept of absorptive capacity: how to realize its potential in the organization field. Organization Science, 21(4), 931-951. http://dx.doi.org/10.1287/ orsc. 1090.0503

Walsh, J. P., \& Ungson, G. R. (1991). Organizational memory. Academy of Management Review, 16(1), 57-91.

Wilkinson, 1., \& Young, L. (2006). On cooperating firms, relations and networks. Journal of Business Research, 55(2), 123-132. http://dx.doi.org/10.1016/ S0148-2963(00)00147-8

Yang, J. (2010). The knowledge management strategy and its effect on firm performance: a contingency analysis. International Journal of Production Economics, 125(2), 215-223. http://dx.doi.org/10.1016/j. ijpe.2010.03.012

Zack, M. H. (1999). Managing codified knowledge. Sloan Management Review, 40(4), 45-48.

Zangiski, M. A. S. G., Lima, E. P., \& Costa, S. E. G. (2013) Organizational competence building and development: Contributions to operations management. International Journal of Production Economics, 144(1),76-89. http:// dx.doi.org/10.1016/j.jpe.2013.01.021

Zarifian, P. (2001). Objetivo competência: por uma nova lógica. São Paulo: Atlas.

Zheng, W., Yang, B., \& McLean, G. N. (2010). Linking organizational culture, structure, strategy and organizational effectiveness: mediating role of knowledge management. Journal of Business Research, 63, 763771. http://dx.doi.org/10.1016/j.jbusres.2009.06.005

\section{Agradecimentos}

Os autores agradecem ao CNPQ e à FAEPEX pelo apoio financeiro cedido para a condução da pesquisa. 


\title{
Knowledge Management: an analysis based on organization contextual factors
}

\begin{abstract}
The latest models of Knowledge Management (KM) recognize four phases: acquisition, storage, distribution and use of knowledge. KM is characterized as a multidisciplinary field, involving both technical and social facets. Due to the diversity of issues surrounding this topic, it is essential to define their study. This research is based on social and coordination studies that seek to identify contextual factors developed internally in organizations that support the $\mathrm{KM}$ process in the automotive industry. To achieve this goal, a quantitative research method based on a surveys was used. The results point to the existence of eight contextual factors that support KM. These factors are mainly related to the human beings responsible for the retention and transformation of common knowledge and the development of an organizational context that encourages the learning process.
\end{abstract}

\section{Keywords}

Knowledge management. Organizational learning. Contextual factors. Automotive sector. Multivariate analysis. 